\title{
Computational Fluid Dynamics-The Futuristic Innovation in Pharmaceutical Industry
}

\author{
Lavanya N, Sayani Bhattacharyya* \\ Department of Pharmaceutics, Krupanidhi College of Pharmacy, Bangalore, Karnataka, INDIA.
}

\begin{abstract}
The review provides an insight into the application of Computational Fluid Dynamics (CFD), a versatile tool for analysis of complex dynamics of air and fluid flow in pharmaceutical operations. The principle of Navier Stokes equation on the explanation of the mathematics on flow of material is outlined in the review. Using the mathematical equations generation of a computer simulated model helps to develop a process, design a device and an operation by fusion of their theoretical background and experimental validation. The use of CFD is gaining importance in the pharmaceutical field as it can trace the critical minor change that leads to a significant impact in the process development. The simulation concept can be useful in terms of identifying and controlling the hazards of these operations on product damage. An outcome of an optimized process, device or operation can be beneficial in each stage of product development and quality build-up. The application of CFD in the development of inhalers, drying process and hydrodynamics of dissolution apparatus is focused here.
\end{abstract}

Key words: Computational fluid dynamics, Navier Stokes equation, Inhaler device, Drying process, Dissolution.

\section{INTRODUCTION}

The flow of fluid is described by the theories of fluid statics, fluid kinematics, and fluid dynamics. The study of the effect of forces on the flow of fluid is termed as fluid dynamics. Application of computer to simulate the effect of forces on the flow of liquid to mimic the real condition is termed as computational fluid dynamics (CFD).

The concept of CFD was evidenced way back to world war II, in the development of the atomic bomb at Los Alamos National Laboratory. ${ }^{1}$ The initial effort on CFD was made by Kopal in 1947. ${ }^{2}$ The topmost creation of the CFD solution was materialized between the 1950s and 1960s. Hall et al. introduced the calculations for inviscid flow. ${ }^{3}$ A breakthrough invention in the supersonic blunt body problem in the aerodynamic field was the most striking aspect reported in this matter. Mathematician J. von Neumann is regarded as the father of CFD for his contribution to artificial viscosity for "capturing" shocks in numerical solutions. ${ }^{4}$ A high-speed digital computer was used as a tool to allow empirical growth. The next cohort of CFD used the Navier Stokes equation to solve the complications. CFD thus created a remarkably close relationship between the theory and experimental aspects of fluid dynamics.

CFD is the branch of science that involves physicists, mathematicians and engineers and establishes a virtual reality of anything that flows regardless of magnitude. It could be the motion of molecules to microchannels, the motion of flame through a combustion chamber, flying of aircraft, the motion of restless atmosphere or water bodies on earth, biomedicine and inhalation therapy etc. ${ }^{5}$

Therefore, CFD is a physical aspect that deals with the study of fluids in motion beyond the range of flow parameters and time scale of experiments. It can account for a minor change in the practical
Submission Date: 08-04-2021; Revision Date: 28-07-2021; Accepted Date: 08-10-2021

DOI: 10.5530/ijper.55.4.193 Correspondence: Prof. Sayani Bhattacharyya, Department of Pharmaceutics, Krupanidhi College of Pharmacy, Bangalore560035, Karnataka, INDIA. Phone: +91-9845561865, Email-sayanibh@gmail. com

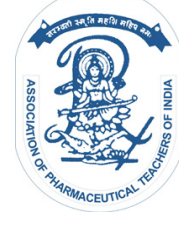

www.ijper.org 
aspect which can bring a significant change on the theoretical aspect and can influence a major variation in the result. The concepts of CFD are based on the conservation of mass, momentum, and energy. This underlying concept can be explained by using several algebraic and partial differential equations, which are briefly outlined in the latter part of the article.

CFD aims to combine both the theoretical and experimental concepts of fluid motion and hence it is considered as the third dimension in fluid dynamics. The modeling equations on a computational grid, provide insight into the exact solution leading to finite-differences in the flow of fluids. CFD cannot replicate the results if the physics of the flow is not clearly incorporated in the modeling. The merge of experimental fluid dynamics with computational fluid dynamics helps to study the divergence in mixing behavior and flow patterns of various types of Non-Newtonian fluids. ${ }^{6}$ In the pharmaceutical field, CFD methods are mainly used for understanding the flow of fluids, testing and optimization of the drying process, blending and segregation operation. With the application of CFD productivity and cost effectiveness can be increased by identifying and controlling the hazards of these operations on the product damage. The application of CFD helps to identify the condemnatory states during the designing of process and apparatus and thus can generate savings for the companies. Hence, CFD methods are used to overcome problems associated with the technology or equipment and are leading the way to develop the process and products on a large scale. ${ }^{7}$

The present review focuses on the application of CFD in the development of specialized pharmaceutical dosage forms and the estimation of the effect on the flow of liquid or heat in various pharmaceutical operations.

\section{PRINCIPLES OF CFD}

CFD principle is based on three core components and they are preprocessing, solution and post processing.

Preprocessing: Preprocessing is done to recognize the area of concern, identify the definite properties of the interest, and design to a correct assumption using different modelling techniques. This leads to the spotting of a recognized area of concern with the interpretation aids to get the finest solution.

Solution: A convergence study of the simulation processes provides the exact solution through the mathematical equations once the difficulty is recognized, and then it is finally computed to get the finite element approximation of the preprocessing design.
Post-processing: To calculate the parameters, systematic analysis of data, verification and validation of the model is done through the generation of various graphs like contour plots, vector plots, data plots etc. This helps to identify the region of interest and do correct simplifications. After the region is defined the computational model is released. ${ }^{8}$

Using the above principle, the parameters associated with the motion of fluids and their mathematical simulations are explained with the three principles of conservation of mass, momentum and energy.

The fundamental identification of three-dimensional motion of fluids associated with complex vortices and turbulence are expressed with the Navier-Stokes equation. The prime properties that play a significant role in the flow of fluid are velocity, pressure, temperature, density, and viscosity of the liquid. The other physical phenomena such as combustion, multiphase flow, turbulence, mass transport, etc., can be categorized into various miscellaneous properties like kinematic, transport, thermodynamic properties etc. ${ }^{9}$

\section{Conservation of mass}

In a controlled volume the mass neither can be created nor destroyed, hence the mass flow difference throughout the system between input and outlet is zero. ${ }^{10}$

The agreement for non-conservation of mass is

$$
\frac{\partial \rho}{\partial t}+\rho(\nabla \cdot u)=0
$$

Where $\rho=$ density, $u=$ velocity $\nabla=$ gradient operator In case of an incompressible liquid the density is constant, and the continuity equation changes to

$$
\frac{\partial \rho}{\partial t}=-\rho(\nabla \cdot u)=0
$$

\section{Conservation of momentum}

According to Newton's second law, the conservation of momentum through the Navier stokes agreement is given as

$$
\rho \frac{\mathrm{Du}}{\mathrm{Dt}}=\mathrm{f}=\mathrm{f}_{\text {body }}+\mathrm{f}_{\text {surface }}
$$

Where $f=$ force exerted per unit volume of fluid particle, $f_{\text {body }}=$ force applied due to gravity on the total mass of fluid particles, $\mathrm{f}_{\text {sufface }}=$ external forces applied on the fluid particles including the viscous drag. 
Therefore, the agreement can be written as

$\rho \frac{\mathrm{Du}}{\mathrm{Dt}}=$ Momentum convection - Massforce + surface force + viscous force

The Navier stokes agreement for the conservation form of momentum for viscous flow can be expressed as

$$
\rho \frac{\mathrm{Du}}{\mathrm{Dt}}=\rho g-\nabla \mathrm{p}+\mu \nabla^{2} \mathrm{u}
$$

Where $\Delta \mathrm{p}=$ surface force and $\mu=$ viscosity coefficient

\section{Conservation of energy}

The assertion of this agreement is the first law of thermodynamics. The general agreement applied to the flow of fluids is as follows

$$
\mathrm{dE}=\mathrm{dQ}+\mathrm{dW}
$$

Where $\mathrm{dE}=$ Rate of change of energy inside the fluid element, $\mathrm{dQ}=\mathrm{Net}$ flux of heat into the element, $d W=$ Rate of work done on the element due to body and surface forces. Generally the energy equation is a function of convective and heat dissipation term involving the enthalpy and thermal conductivity. ${ }^{8}$

\section{APPLICATIONS IN PHARMACEUTICAL INDUSTRY}

Elemental functioning in the pharmaceutical industry controls a huge quantity of fluids and powders. To analyze unit operations such as mixing, separation, drying, fluid transport, and heat generation the concept of CFD can be applied. The combination of CFD with the process of product development helps in the optimization of the process, minimized power requirement and it also helps to minimize the time for marketing. Hence, a little increase in efficiency shows a maximum increase in the economy. ${ }^{7}$ CFD also allows the analysis of various drug delivery designs rapidly and economically using a 3D model of human physiology. CFD plays a very prominent role in the development of nasal spray, inhaler development, and helps to study the effect of parameters in drying, dissolution, etc as shown in Figure $1 .{ }^{11}$

\section{Particle deposition study analysis for nasal delivery}

Experimental activities on nasal drug delivery are very less compared to pulmonary drug delivery. The walls of the nose are highly vascularized hence the therapeutic drug directly goes to the systemic circulation, thereby avoids the first-pass metabolism of the drug. A delivery to the brain through the olfactory nerves can also be targeted by this route of administration. Nasal delivery
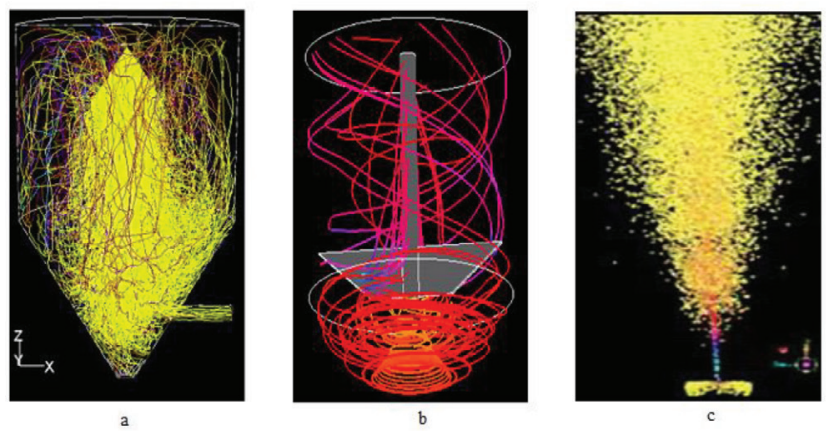

Figure 1: CFD applications in a. Spray Drying, b. Dissolution process c. pMDI spray.

offers a rapid onset of action, patient compliance, and painless administration compared to injections. The particle deposition from the nasal spray occurs in the nasal valve region. Computational fluid and particle dynamics (CFPD) were used in conjunction with experiments to predict the particle dynamics and final deposition in the nasal cavity. The major challenges outlined in the delivery of drugs to the nasal cavity were the requirement of power to disperse the drug in the nasal cavity, and the unexpected loss of drug during actuation. ${ }^{12}$ The principle of nasal delivery identifies that the physicochemical properties of therapeutic drugs can also influence the rate of absorption. The penetration of particles to the mucus layer has a minimal effect on the absorption of the drug. ${ }^{13}$ The concept of CFD modelling in nasal delivery can help in developing a safe and efficient device and thus can decrease the time required for a clinical trial and marketing approval. ${ }^{14}$

\section{Computational modelling of nasal spray}

Nasal delivery provides the highest regional precipitation of drugs. To develop a nasal spray it is necessary to have a comprehension of both atomization and deposition of particles to enhance the optimization of a nasal spray. ${ }^{15}$

Cheng YS et al. studied the precipitation of particles from a nasal spray by constructing a nasal airway replica model. The particle precipitation was found to occur mainly in the preceding and turbinate regions. The precipitation at the preceding region increased with an increase in spray cone angle and particle size. ${ }^{16}$ Inthavong $\mathrm{K}$ et al. explored that the precipitation of particles in the anterior region of the nose was influenced by the particle size, the diameter of the spray cone, and the spray cone angle. The swirled fraction of the sprayed dose was affected by the particle size and led to the change in the deposition site. They concluded that 
incorporation of swirl fraction into narrowing spray enhanced better penetration of the larger particles in nasal cavity. ${ }^{12}$ Inthavong $\mathrm{K}$ et al. in another study investigated on the precipitation of particles in the nasal cavity from a spray device. It was observed that placing the spraying device at the vestibule enhanced the flow disturbance. The precipitation of particles was high in the anterior region due to inertia. ${ }^{17}$ Kimbell JS et al. confirmed that the spray behavior, particle deposition, the limitations of nasal sprays and also the potential ways to improve the functionality and penetration of the particles could be studied efficiently by CFD modelling. ${ }^{18}$ Kiaee $\mathrm{M}$ et al. had done elaborated simulation modelling through CFD on the nasal spray deposition in six different regions of the nasal gateway in a wide parameter space like particle size, spray angle, spray direction, spray injection speed and location. It was found that the penetration of particles through the nasal spray was highly dependent on the size of particles. ${ }^{19}$ The efficiency of computational modelling on nasal spray is depicted at Figure 2.

\section{Identification of challenges in the development of inhaler}

Inhalers are mainly used for the delivery of drugs to the lower respiratory tract. They provide a systemic effect through localization at the target site and enhance the bioavailability of the drug. The commonly available inhalers are dry powder inhalers and metered dose inhalers. The additional merits of inhaler include minimization of the loss of drug and rapid onset of action. The deposition rate depends on particle size, the hindrances on the flow of particles due to the branching of the trachea, the viscosity of the mucous, formation of biofilm during infection and rate of inspiration by the patient. ${ }^{11,20}$

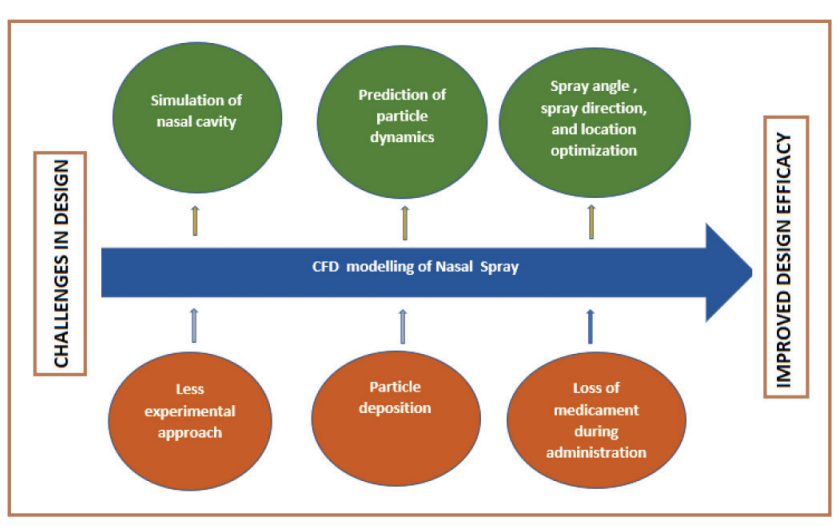

Figure 2: CFD modelling of Nasal spray to overcome the challenges in nasal delivery.

\section{Pressurized metered dose inhalers (pMDIs)}

The pressurized metered-dose inhaler contains a solution or suspension of drug in a propellant which on actuation produces evanescent, cavitating, and turbulent fluid that flashes into rapidly evaporating droplets. pMDIs are used mainly in the treatment of lung disorders such as asthma, cystic fibrosis, emphysema, etc. alveolar epithelium absorbs most of the drugs.

Oliveira RF et al. explored the potential parameters of pMDI spray by using Fluent $\mathrm{M}$ software. It was able to detect each particle velocity and position after actuation as of real life pMDI spray through the simulation. Hence the software could correlate the accelerated zone of airflow and the position of the particles. ${ }^{21}$ Oliveira $\mathrm{RF}$ et al. in another study, reported the spray plume analysis of pMDI containing salbutamol and HFA-134a. The spray plume produced a transient jet whose effects were related to the pressure of actuation. The microscopy study reported that the shape of the particles was irregular and the aerodynamic size distribution fitted the Log-normal distribution. ${ }^{22}$ Kleinstreuer $\mathrm{C}$ et al. analyzed the computational model of pMDI. The simulation was done through a validated CFD model. The airflow, transport of the droplet from the spray and particle deposition after actuation from a pMDI were evaluated with the study of the critical parameters like the type of propellants, nozzle diameters, and the type of spacer used. The beneficiary effect of HFA-pMDI was found when it could deposit a significant amount of particles in the lungs with a nozzle diameter of $0.25 \mathrm{~mm} \cdot{ }^{23} \mathrm{Abd}$ Rahman MF et al. investigated on the effect of actuator nozzle angle in determining the particle velocity from a pMDI system using ANSYS Fluent Version 19.2 software. With the use of K-epsilon function and discrete particle model, the velocity of particles reaching the acinar region of the lungs was studied. The highest turbulent kinetic energy was seen at an actuator nozzle angle of $120^{\circ}$ and at that energy, the velocity magnitude of the particle could able to fly the particle to the alveolar region. ${ }^{24}$

\section{Dry powder inhalers (DPIs)}

Dry powder inhalers are commonly used for the delivery of a powder form of active therapeutic agent. The basic principle of DPIs is the dispersion of small powder particles for inhalation and delivery to the lungs. They are inspiratory flow driven device. The micro dispersion of the particle through the device to reach the pulmonary site is the main challenge associated with it. Milenkovic $\mathrm{J}$ et al. explored the particle motion and deposition in a dry powder inhaler - Turbuhaler through CFD. The Turbuhaler DPI geometry was created in CATIA v519 
software. The model integrated the dynamic flow, the particle motion and the collision between particle and wall of the DPI. The major problems associated with DPI were that the particle deposition, dispersion of particles, aggregation breakup, and precipitation of particles. These parameters were studied at different peak of inspiratory flow rates, flow increase rates and particle injection times to trace the impact on particle deposition and dispersion. ${ }^{25}$

The earliest CFD studies on DPIs were conducted by Coates et al. ${ }^{26-28}$ A sequence of studies was conducted on the geometry of the mouthpiece, grid structure and length of mouthpiece, the size and presence or absence of capsule, rate of flow, inlet size for entry of air, and performance of inhaler. The results showed that with an increase in grid size of the mouthpiece there was a reduction in particle deposition. Mouthpiece with a tapered diameter minimized the precipitation of particles at the throat. The size of the capsule did not affect the production of particles. Wong $\mathrm{W}$ et al. reviewed the use of computational approaches in inhaler development. It was reported that both CFD and Digital evaluation model (DEM) were efficacious in evaluating the performance of various inhalation devices and formulations. Hence it was found that CFD simulation alone could be limited in predicting the break-up of agglomerates, but both the approaches could be used to measure accurately the particles motion and the break-up of agglomerates. ${ }^{29}$

\section{Optimization of drying parameters}

Drying is a process of mass transfer consisting of the removal of water or any other solvents by evaporation from a solid, semi-solid, or liquid. There are mainly two types of dryers - direct and indirect. The classification is based on the method of heat transfer. In the direct dryers, the feed material is in direct contact with the heated air. Examples of direct thermal drying systems are flash, rotary, belt, fluidized bed, spray, and tray dryers. In indirect dryers, the wet feed is dried using conductive heat transfer process from a hot surface. Examples of indirect dryers are paddle, multi-effect evaporator, and disc dryers. The main aim of the drying process is the removal of unwanted water or any other solvents from the feed that helps to achieve the final pharmaceutical product or prevent the feed from deterioration. ${ }^{30}$

\section{Spray dryer}

Spray drying is a unit operation of conversion of liquid feed into dry particles. The liquid feed after atomization, are mixed with hot gas in the spray chamber. Evaporation of the moisture in the droplets of the original feed settles as spherical particles. Spray drying is suitable for drying thermo-sensitive materials such as food products as it offers a high surface area with less drying time. Spray dryers are widely used in the food, pharmaceutical, and chemical industries. The essential requirement for a spray dryer is that the drying materials should be in powder form. ${ }^{31}$ The merits of spray dryers are that they can handle thermo-sensitive, non-sensitive, and heat resistant fluids. They can also produce materials of controllable particle size, shape, and form. There is no risk of explosion. The demerits are high installation costs and low thermal efficiency. The spray dryers are mainly used in agrochemical, biotechnological products, fine and heavy chemicals, pharmaceuticals, dairy products, and the food industry. Researcher Oakley DE et al. in their multiple studies reported that to get correct and consistent results, the inlet parameters of the spray dryer should be précised. For the swirling flow of the atomized spray, the Reynolds stress model was found to account for accurate results. The study on the water droplet trajectories revealed that the rate of drying was maximum at the recirculation zone. The superheated steam showed a difference in flow patterns at all zones of the spray dryer but not at the recirculation zone. Particles with smaller size dried more quickly than medium size particles. ${ }^{31,32}$ Southwell and Langrish observed that there was unpredictable mixing in the non-swirl model because the spraying was from the bottom of the dryer. For the moderate swirl model, the high centrifugal force enhanced the mixing of spray and air. Spraying was uniform in the high swirl model..$^{33}$ Sadripour M et al. studied the deposition of drug and excipients on the wall of the spray dryers using computer simulation. The precipitation of drugs at the wall was found to be reduced mainly by reduction of the flow rate of feed. It was observed that when the concentration of particles was high the chances of precipitation of particles at walls was enhanced. The amount and place of particle deposition were mostly influenced by the initial diameter of particles. ${ }^{34}$

\section{Fluidized bed dryer}

It is a type of direct dryer which is designed to dry products as they float with the support of air. Compared to dry particles the particles with high initial moisture content require a high minimum fluidization velocity. Only the upper part of the bed of solids is in the fluidized state as the wet surface experiences a cohesive force. During the initial stage of drying process, the bottom layer remains as immobile. The pharmaceutical industry uses this fluidized bed processor for 
various unit operations like mixing, drying, granulation, and coating. The numerous factors which affect the quality of the final product are the design of the apparatus, physiochemical factors of the material to be dried, operational parameters. This fluidized bed processor has high thermal efficiency. This type of drying process is used in the drying of chemicals, carbohydrates, and drug-excipients mix in pharmaceuticals. ${ }^{30}$

The CFD simulation and optimization of factors affecting the performance of fluidized bed dryer is a function of size of particles, depth of the bed and maximum inlet air temperature resulted in an increase in the utilization of energy and minimized the loss of energy from the outlet. Qiao et al. reported that an increase in supercritical gas velocity raised the temperature of particles that led to a decrease in moisture content. This could be attributed to the enhanced heat and mass transfer between bubbles and particles. ${ }^{35}$ Ranjbaran $\mathrm{M}$ et al. investigated the two-fluid Eulerian multiphase model. They found that increase in power density enhances the rate of drying because of high generation of heat. ${ }^{36} \mathrm{Li} \mathrm{Z}$ et al. explored the flow behavior and bubble characteristics of a pulse fluidized bed via CFD modeling using the Eulerian-Eulerian two-fluid modeling approach. It was reported that the instabilities in flow and drop in pressure were due to the production and movement of bubbles. $^{37}$

\section{HVAC}

Heating ventilation air Conditioning (HVAC) system helps to keep the air free of dust particles indoors of parenteral formulation area. Plenum, inlet, blower, module, and ducts are the components of an HVAC system. $^{38}$

Cartwright $\mathrm{M}$ et al. explored the HVAC design and optimization using CFD and they found that CFD was applied to HVAC to study the flow of air in various designs within a short duration of time. It was easy to study the control on temperature, orientation of walls, and the exchange of heat in walls by a simulation of HVAC. The simulation could minimize the time required for the modification of the HVAC system. ${ }^{39}$

\section{Designing of dissolution test}

Dissolution is expressed in terms of the process of mass transfer. Mass transfer is a combination of both thermodynamics and hydrodynamics. If absorption of the drug is by diffusion then hydrodynamics is the primary concern. ${ }^{40}$ Dissolution tests are more popular in the pharmaceutical industry because these tests are used to optimize the release of drug from the dosage, to find batch to batch variability, to detect any changes on storage and a vital study for regulatory approval of any solid orals. There are numerous challenges in the dissolution process starting from the selection of dissolution apparatus, dissolution media and experimental conditions required to be maintained. Numerous types of inaccuracy can occur in estimation due to alignment of the vessel, the curvature of the vessel, positioning of the paddle or basket and sampling technique, etc. ${ }^{41}$

Diebold SM et al. explored the various physiological parameters involved in dissolution testing. They compared the physiological parameters of paddle and basket type apparatus. They found that the velocity of the fluid in the paddle apparatus was maximum compared to the basket type. The hydrodynamic region below the basket was appeared to be more separated than the paddle-type apparatus. A higher flow rate was achieved by using low fluid volume in the dissolution apparatus. Hence they concluded that the volume of dissolution fluid also plays a major role in determining the rate of dissolution at a given hydrodynamic condition. ${ }^{40}$ Darcy DM et al. Mccarthy LG et al. and Bai GE et al. in their various studies explored that the positioning of tablet at the center of the dissolution basket, the dissolution rate was found to be very less compared to tablets positioned away from the center. The tablet placed in the center position experienced minimum velocity because of vortex formation and rotation of the paddle. From the above results, it was concluded that change in position of the tablet would have a great influence on the rate of dissolution. ${ }^{4244}$ Darcy DM et al. also explored on the in vitro-in vivo correlation using CFD. Levy beaker was used to study the effect of hydrodynamics in correlating in vitro-in vivo conditions. The agitation of fluid was caused by the rotation of the stirrer produces tangential flow in the levy beaker apparatus. Regions of high velocity were seen in the levy beaker apparatus at $59 \mathrm{rpm}$. It was observed that the dissolution rate was also affected by the direction of rotation of the stirrer..$^{45}$ Ameur $\mathrm{H}$ et al. explored hydrodynamic studies in the paddle dissolution apparatus. They observed the non-uniformity in shear rate inside the media and found that the shear rate was very less at the center of the vessel. They found that the shape of the vessel had an impact on the rate of shear hence they concluded that dished bottom shows good mixing than the flat bottom vessel. ${ }^{46}$

A summarized table of CFD applications in various field of pharmacy with the potential parameters to be considered is listed in Table 1. 
Table 1: Brief of potential parameters studied by CFD for various pharmaceutical applications.

\begin{tabular}{|c|c|c|}
\hline SL No & Applications & Parameters to consider \\
\hline 1 & Nasal Spray & $\begin{array}{l}\text { Spray cone angle, particle size, } \\
\text { diameter of the spray cone, spray } \\
\text { direction, spray injection speed } \\
\text { and location, spray behavior, spray } \\
\text { direction, spray injection speed and } \\
\text { location. }{ }^{12,16,18,19}\end{array}$ \\
\hline 2 & pMDI & $\begin{array}{c}\text { Particle velocity, spray plume, airflow, } \\
\text { transport of the droplet, actuator } \\
\text { nozzle angle. }{ }^{22-24}\end{array}$ \\
\hline 3 & DPIs & $\begin{array}{l}\text { Geometry of the mouthpiece, grid } \\
\text { structure and length of mouthpiece, } \\
\text { the size and presence or absence } \\
\text { of capsule, rate of flow, inlet size } \\
\text { for entry of air, and performance } \\
\text { of inhaler, particles motion and the } \\
\text { break-up of agglomerates. }{ }^{26,27,29,27}\end{array}$ \\
\hline 4 & Spray Dryer & $\begin{array}{l}\text { Inlet parameters of the spray } \\
\text { dryer, swirling flow of the atomized } \\
\text { spray, study on the water droplet } \\
\text { trajectories, positions of the nozzle, } \\
\text { centrifugal force between the spray } \\
\text { and circulated air, and concentration } \\
\text { of the spray drying solution. }{ }^{31,33,34}\end{array}$ \\
\hline 5 & $\begin{array}{l}\text { Fluidized bed } \\
\text { dryer }\end{array}$ & $\begin{array}{c}\text { Size of particles, depth of the } \\
\text { bed, inlet air temperature, effect } \\
\text { of heat, flow behavior and bubble } \\
\text { characteristics of a pulse fluidized } \\
\text { bed. }{ }^{36,37}\end{array}$ \\
\hline 6 & HVAC & $\begin{array}{c}\text { Temperature control, orientation of } \\
\text { walls, and the exchange of heat in } \\
\text { walls. }{ }^{39}\end{array}$ \\
\hline 7 & $\begin{array}{l}\text { Dissolution } \\
\text { process }\end{array}$ & $\begin{array}{l}\text { Velocity of fluid, rate of flow, position } \\
\text { of tablet, rate of shear. } 40,42,43,46\end{array}$ \\
\hline
\end{tabular}

\section{CONCLUSION}

Merging theoretical concept and experimental validation of a process or a device through computer simulation using different mathematical models can be a successful outcome in pharmaceutical operations. Here lies the benefit of the application of CFD. The use of CFD is already established in the aerospace and automotive industries. In case of pharmaceutical product development and optimization, CFD techniques can also be used as a powerful tool. It may render a development flawless at the initial stage by its capability to identify the critical factors. The reported studies discussed in the review on the development of inhaler, dryer and dissolution analysis proved the efficacy of CFD in identifying the pivotal points in measuring the efficacy of the techniques.

\section{ACKNOWLEDGEMENT}

We are truly indebted to the Principal and Management of Krupanidhi College of Pharmacy, Bangalore for their support to carry out the review work.

\section{CONFLICT OF INTEREST}

The authors declare no conflict of interest.

\section{ABBREVIATIONS}

CFD: Computational Fluid Dynamics; CFPD: Computational Fluid and Particle Dynamics; 3D: Three Dimensional; DEM: Digital evaluation model; DPIs: Dry Powder Inhalers; HFA: Hydro Fluoro Alkane; HVAC: Heating ventilation air Conditioning; pMDIs: Pressurized Metered Dose Inhalers.

\section{REFERENCES}

1. Our history [cited Dec 21 2020]. Available from: https://www.lanl.gov/about/ history-innovation/index.php.

2. Computational fluid dynamics || Basic Philosophy of CFD - [PDF Document] [cited Dec 21 2020]. Available from: https://fdocuments.in/document/ computational-fluid-dynamics-basic-philosophy-of-cfd.html.

3. Joseph Hall E, Joseph E. Retrospective Theses and Dissertations Application of viscous-inviscid interaction to separated flows with heat transfer including rearward-facing step flows Recommended. Citation Publishing [cited Dec 21 2020]. Available from: http://lib.dr.iastate.edu/rtd.

4. van Leer B, Powell KG. Introduction to computational fluid dynamics. Encycl Aerosp Eng. 2010:1-14

5. Computational fluid dynamics - Wikipedia. [cited Jan 3 2021]. Available from: ttps:. Available from: http://en.wikipedia.org/wiki/Computational_fluid_ dynamics.

6. Kukura J, Arratia PC, Szalai ES, Bittorf KJ, Muzzio FJ. Pharmaceutical flows. Pharm Technol. 2002;26:48-72.

7. Pordal HS, Matice CJ, Fry TJ. The role of computational fluid dynamics in the pharmaceutical industry. Pharm Technol. 2002;26(2):72-9.

8. CFD post-processing tips to improve visualization productivity and quality. Avaiable from. CFD Post-Process Tips Improve Vis Prod Qual | Southland Industries.

9. What are the Navier-Stokes equations? SimScale Numerics.

10. Navier-Stokes equations. [cited Feb 2 2021]. Available from:https:// NavierStokes Eqn.pdf. Available from: caltech.edu.

11. Karanjkar A. CFD in the design of drug delivery systems Computational fl uid dynamics (CFD) enables a fast and cost-effective eval- uation of new drug delivery designs and formulations [cited Feb 2 2021]. Available from: https:// IPT0312-page65-122. Available from: iptonline.com.

12. Inthavong K, Tian ZF, Tu JY, Yang W, Xue C. Optimising nasal spray parameters for efficient drug delivery using computational fluid dynamics. Comput Biol Med. 2008;38(6):713-26. doi: 10.1016/j.compbiomed.2008.03.008, PMID 18468593

13. Rygg A, Hindle M, Longest PW. Absorption and clearance of pharmaceutical aerosols in the human nose: effects of nasal spray suspension particle size and properties. Pharm Res. 2016;33(4):909-21. doi: 10.1007/s11095-0151837-5, PMID 26689412.

14. Kleven M, Melaaen MC, Reimers M, Røtnes JS, Aurdal L, Djupesland PG. Using Computational Fluid Dynamics (CFD) to improve the bi-directional nasal drug delivery concept. Food Bioprod Process. 2005;83(2):107-17. doi: 10.1205/fbp.04403.

15. Schroeter JD, Kimbell JS, Asgharian B. Analysis of particle deposition in the turbinate and olfactory regions using a human nasal computational 
fluid dynamics model. J Aerosol Med. 2006;19(3):301-13. doi: 10.1089/ jam.2006.19.301, PMID 17034306.

16. Cheng YS, Holmes TD, Gao J, Guilmette RA, Li S, Surakitbanharn Y, Rowlings $\mathrm{C}$. Characterization of nasal spray pumps and deposition pattern in a replica of the human nasal airway. J Aerosol Med. 2001;14(2):267-80. doi: 10.1089/08942680152484199, PMID 11681658.

17. Inthavong K, Ge Q, Se CMK, Yang W, Tu JY. Simulation of sprayed particle deposition in a human nasal cavity including a nasal spray device. J Aerosol Sci. 2011;42(2):100-13. doi: 10.1016/j.jaerosci.2010.11.008.

18. Kimbell JS, Segal RA, Asgharian B, Wong BA, Schroeter JD, Southall JP, Dickens CJ, Brace G, Miller FJ. Characterization of deposition from nasal spray devices using a computational fluid dynamics model of the human nasal passages. J Aerosol Med. 2007;20(1):59-74. doi: 10.1089/jam.2006.0531, PMID 17388754.

19. Kiaee M, Wachtel H, Noga ML, Martin AR, Finlay WH. Regional deposition of nasal sprays in adults: A wide ranging computational study. Int J Numer Method Biomed Eng. 2018;34(5):e2968. doi: 10.1002/cnm.2968, PMID 29453801.

20. Bhattacharyya S, S Sogali BS. Inhalation therapy - Approaches and challenges. Asian J Pharm Clin Res. 2018;11(4):9-16. doi: 10.22159/ ajpcr.2018.v11i4.24117.

21. Oliveira RF, Teixeira S, Silva LF, Teixeira JC, Antunes H. Study of a pressurized metered-dose inhaler spray parameters in Fluent ${ }^{\mathrm{TM}} ; 2010$.

22. Oliveira RF, Ferreira AC, Teixeira SF, Teixeira JC, Marques HC. PMDI spray plume analysis: ACFD study. Lect Notes Eng Comput Sci. 2013;3:1883-8.

23. Kleinstreuer $\mathrm{C}$, Shi $\mathrm{H}$, Zhang Z. Computational analyses of a pressurized metered dose inhaler and a new drug-aerosol targeting methodology. J Aerosol Med. 2007;20(3):294-309. doi: 10.1089/jam.2006.0617, PMID 17894536.

24. Rahman MFA, Asmuin NZ, Taib I, Mat MNH, Khairulfuaad R. Influence of actuator nozzle angle on the flow characteristics in pressurized-metered dose inhaler using cfd. 2020;12(6):67-79.

25. Milenkovic J, Alexopoulos AH, Kiparissides C. Deposition and fine particle production during dynamic flow in a dry powder inhaler: a CFD approach. Int J Pharm. 2014;461(1-2):129-36. doi: 10.1016/j.ijpharm.2013.11.047, PMID 24296048.

26. Coates MS, Chan HK, Fletcher DF, Raper JA. Influence of air flow on the performance of a dry powder inhaler using computational and experimental analyses. Pharm Res. 2005 Sep;22(9):1445-53. doi: 10.1007/s11095-0056155-x, PMID 16132356.

27. Coates MS, Chan HK, Fletcher DF, Raper JA. Effect of design on the performance of a dry powder inhaler using computational fluid dynamics. Part 2: Air inlet size. J Pharm Sci. 2006;95(6):1382-92. doi: 10.1002/jps.20603, PMID 16625656.

28. Coates MS, Fletcher DF, Chan HK, Raper JA. Effect of design on the performance of a dry powder inhaler using computational fluid dynamics. Part 1: Grid structure and mouthpiece length. J Pharm Sci. 2004;93(11):2863-76. doi: 10.1002/jps.20201, PMID 15389665.

29. Wong W, Fletcher DF, Traini D, Chan HK, Young PM. The use of computational approaches in inhaler development. Adv Drug Deliv Rev. 2012;64(4):312-22. doi: 10.1016/j.addr.2011.10.004, PMID 22063020.
30. Jamaleddine TJ, Ray MB. Application of computational fluid dynamics for simulation of drying processes: a review. Drying Technology. 2010;28(2):120-54. doi: 10.1080/07373930903517458.

31. Oakley DE, Bahu RE. Computational modelling of spray dryers. Comput Chem Eng. 1993;17:S493-8. doi: 10.1016/0098-1354(93)80271-N.

32. Oakley DE. Scale-up of spray dryers with the aid of computational fluid dynamics. Drying Technology. 1994;12(1-2):217-33. doi: 10.1080/07373939408959954.

33. Southwell DB, Langrish TAG. Observations of flow patterns in a spray dryer. Drying Technology. 2000;18(3):661-85. doi: 10.1080/07373930008917731.

34. Sadripour M, Rahimi A, Hatamipour MS. Experimental study and CFD modeling of wall deposition in a spray dryer. Drying Technology. 2012;30(6):574-82. doi: 10.1080/07373937.2011.653613.

35. Qiao Z, Wang Z, Zhang C, Yuan S, Zhu Y, Wang J. PVAm-PIP/PS composite membrane with high performance for $\mathrm{CO}_{2 / \mathrm{N} 2}$ separation. AIChE J. 2012;59(4):215-28.

36. Ranjbaran M, Zare D. CFD modeling of microwave-assisted fluidized bed drying of moist particles using two-fluid model. Drying Technology. 2012;30(4):362-76. doi: 10.1080/07373937.2011.642913.

37. Li Z, Su W, Wu Z, Wang R, Mujumdar AS. Investigation of Flow Behaviors and Bubble Characteristics of a Pulse Fluidized Bed via CFD Modeling. Drying Technology. 2009;28(1):78-93. doi: 10.1080/07373930903430785.

38. Tashtoush B, Molhim M, Al-Rousan M. Dynamic model of an HVAC system for control analysis. Energy. 2005;30(10):1729-45. doi: 10.1016/j. energy.2004.10.004.

39. Cartwright M, Huang LJ. HVAC system design and optimization utilizing computational fluid dynamics. SAE Tech Pap. 1997.

40. Diebold SM. Physiological parameters relevant to dissolution testing: hydrodynamic considerations. Pharm Diss Test. 2005:127-91.

41. D'Arcy DM, Corrigan OI, Healy AM. Evaluation of hydrodynamics in the basket dissolution apparatus using computational fluid dynamics - Dissolution rate implications. Eur J Pharm Sci. 2006;27(2-3):259-67. doi: 10.1016/j. ejps.2005.10.007, PMID 16314078.

42. D'Arcy DM, Corrigan OI, Healy AM. Hydrodynamic simulation (computational fluid dynamics) of asymmetrically positioned tablets in the paddle dissolution apparatus: impact on dissolution rate and variability. J Pharm Pharmacol. 2005;57(10):1243-50. doi: 10.1211/jpp.57.10.0002, PMID 16259752.

43. McCarthy LG, Kosiol C, Healy AM, Bradley G, Sexton JC, Corrigan OI. Simulating the hydrodynamic conditions in the United States Pharmacopeia paddle dissolution apparatus. AAPS PharmSciTech. 2003;4(2):E22. doi: 10.1208/pt040222, PMID 12916904.

44. Psimadas D, Georgoulias P, Valotassiou V, Loudos G. Molecular nanomedicine towards cancer: ${ }^{111}$ In-labeled nanoparticles. J Pharm Sci. 2012;101(7):2271-80. doi: 10.1002/jps.23146, PMID 22488174.

45. D'Arcy DM, Healy AM, Corrigan OI. Towards determining appropriate hydrodynamic conditions for in vitro in vivo correlations using computational fluid dynamics. Eur J Pharm Sci. 2009;37(3-4):291-9. doi: 10.1016/j. ejps.2009.02.016, PMID 19491018.

46. Ameur H, Bouzit M. 3D hydrodynamics and shear rates' variability in the United States Pharmacopeia Paddle Dissolution Apparatus. Int J Pharm. 2013;452(1-2):42-51. doi: 10.1016/j.jpharm.2013.04.049, PMID 23680733. 
PICTORIAL ABSTRACT

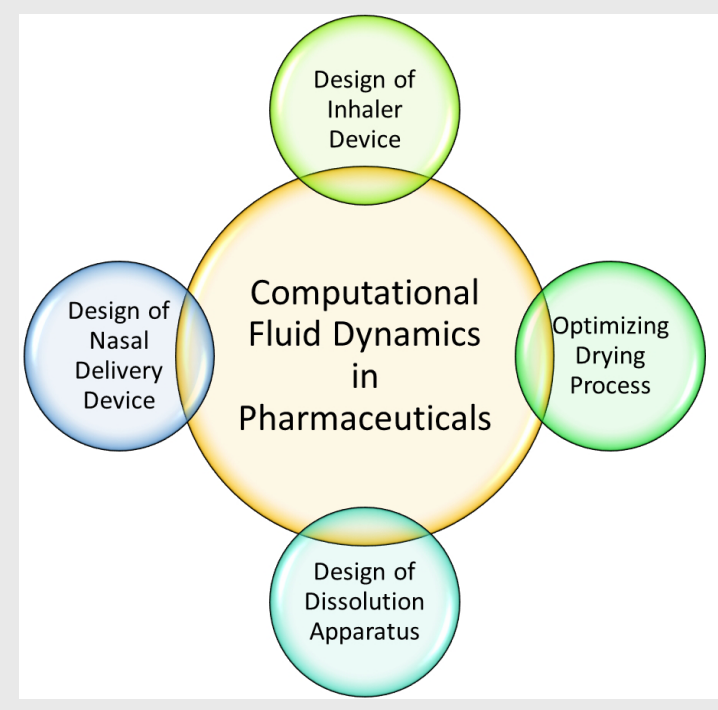

\section{SUMMARY}

CFD is a state-of-the-art technology for developing and validating pharmaceutical operations, using the principle of Navier Stokes equation. The flow of fluid, air or particle is a crucial factor in many of the pharmaceutical unit operations. The hinderance of the flow may render a process or a device incapable. Hence through computer simulation the minor change which leads to the major defect in the process can be easily identified, hazards can be controlled, and product damage can be minimized. Thus, the use of CFD can help in the perfect designing of process, apparatus and technology and can increase the productivity and cost effectiveness for large scale manufacturing and easy regulatory approval for certain medical devices.

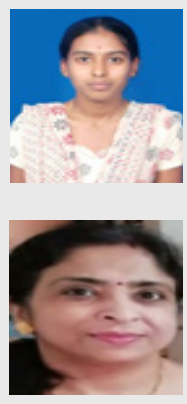

Lavanya $\mathbf{N}$, is a PG scholar in the Department of Pharmaceutics, Krupanidhi College of Pharmacy, Bangalore. She has keen interest in novel drug delivery system and computer applications in pharmaceuticals.

Sayani Bhattacharyya is working as a Faculty in the Department of Pharmaceutics, Krupanidhi College of Pharmacy, Bangalore. Her interest in novel drug delivery system and nano carriers mediated formulation has brought many national and international publications in reputed journals. She has 19 years of teaching and research experience.

Cite this article: Lavanya N, Bhattacharyya S. Computational Fluid Dynamics - The Futuristic Innovation in Pharmaceutical Industry. Indian Journal of Pharmaceutical Education and Research. 2021;55(4):930-8. 